\title{
A FRAMEWORK TO ASSIST IN THE ANALYSIS OF RISKS AND REWARDS OF ADOPTING BIM FOR SMES IN THE UK
}

\author{
Thep Thanh LAM, Lamine MAHDJOUBI, Jim MASON \\ Department of Architecture and Built Environment, the University of the West of England, \\ Bristol, United Kingdom
}

Received 22 Feb 2016; accepted 24 Oct 2016

\begin{abstract}
Building information modelling (BIM) adoption amongst larger construction firms and innovators seems to be on the increase. However, there is evidence to suggest that small and medium sized enterprises (SMEs) are currently lagging behind and are losing out in winning publicly funded projects. Guidance and frameworks to assist SMEs to make an informed decision about BIM adoption are currently lacking. There has been no systematic effort to date to bring together the results of research in SMEs' BIM adoption. Consequently, this paper seeks to bridge this gap and provide a conceptual framework to give a theoretical foundation to the study of brokering risks and rewards in the adoption of BIM for project delivery. This framework is comprehensive and includes trading off risks and rewards associated with several criteria, such as stage of involvement, project value, funding, and the procurement route chosen. The approach has been validated by a representative sample of BIM users and the findings of the validation are also presented. The findings of the framework validation reveal that early design stage, project size between $£ 5 \mathrm{~m}$ and $£ 50 \mathrm{~m}$, private funding, and integrated project delivery procurement are the best opportunities that enable SMEs to maximise the benefits and minimise the risks, when adopting BIM.
\end{abstract}

Keywords: BIM, risk, reward, SMEs, involvement phase, project value, source of funding, procurement route.

\section{Introduction}

Building information modelling (BIM) is emerging as the industry standard approach to the modelling and management of building lifecycles from design and construction through to maintenance and eventual demolition. UK Government's Construction Strategy has pushed forward the programme for adopting BIM. BIM Level 2 became compulsory on publicly procured projects from April 2016. Consequently, future bidders on public building projects are required to work collaboratively through 3D models and exchange information based on standards such as the PAS 1192-2:2013. Specification for information management for the capital/delivery phase of construction projects using building information modelling (NBS 2013). More recently, there has been a wider drive to push the whole industry to embrace BIM so that it can capitalise on the benefits it confers (RICS 2014). BIM usage in the UK's construction industry has recorded a significant increase over the last few years. The survey published by the National Building Specification (NBS) shows that the percentage of industry using BIM rose from $13 \%$ in 2010 to $39 \%$ in 2012 . Fifty-four percent of industry is not using BIM but is aware of it while $77 \%$ said that they would be using it in the next year (NBS 2013).

However, BIM adoption primary concerns large companies. Smaller companies are still slow in embracing the new technology (SmartMarket Report 2012). Indeed, small and medium sized enterprises (SMEs) are lagging behind in BIM adoption and are losing out in winning publicly funded projects and potentially private sector ones too. It emerged that $40 \%$ of construction SMEs lose out on $90 \%$ of the public sector work they bid for, while more than half of SMEs claim to have identified a reduction in their rate of success in bidding for public sector contracts over the past five years (Federation of Master Builders 2013).

Blackwell (2012) warns that SMEs could well lose contracts in both the domestic and international markets if they remain slow in grasping and adopting BIM as a transformative technology and process. Losing out on business results in the SMEs feeling less competitive and

Corresponding author: Thep Thanh Lam

E-mail: thanh2.lam@live.uwe.ac.uk 
innovative in comparison with their competitors (Harris 2013). This trend may continue if SMEs do not pay attention to investing in new technology and reforming their organisations in order to meet with the requirements of the industry.

SMEs seem to favour private projects where no BIM mandate exists. This sector is now a targeted area; the purpose being to "rescue" SMEs from losing business in the BIM environment. However, recent reports indicate that around two thirds of both public sector (65\%) and private sector $(70 \%)$ UK owners state that they will require BIM on their projects compared to $30 \%$ of US public owners and just $11 \%$ of US private sector ones (SmartMarket Report 2014). Therefore, over-reliance on private sector works is not a viable option. These statistics ought to rouse SMEs from traditional approaches and encourage new strategies to adopt new technology and collaborative practices.

It appears that SMEs are yet to be convinced that BIM is beneficial to them, and remain concerned about the potential risks to their business. It appears that guidance and frameworks to assist SMEs in making an informed decision about BIM adoption are currently lacking. This paper reports on the development of a conceptual framework to assist in the analysis of the risks and rewards of adopting BIM by SMEs in project delivery. The findings of the framework validation are also presented. The paper is divided into six sections. The introduction section presents the background knowledge and the research gap. Section 1 addresses current efforts to improve BIM adoption for SMEs. Section 2 examines the key factors affecting BIM adoption and details the rationale for the development of a conceptual framework. Section 3 outlines the adopted research methodology. Results and discussion of the validation of the framework are examined in Section 4. The conclusion section summarises the results and the contribution of the paper to existing knowledge as well as future research work.

\section{BIM adoption by SMEs}

Increasing BIM usage amongst SMEs is a key condition for achieving the transformation of the construction industry through BIM. SMEs are widely considered to be the backbone of major economies around the world (Love et al. 2004). An SME is usually defined by its characteristics including number of staff, turnover, asset size and capital requirement (Ibrahim et al. 1986; Hsu et al. 2012). In 2010 Canadian SMEs employed approximately $48 \%$ of the private sector workforce (Industry Canada 2011 ) and $85 \%$ of new jobs were created by SMEs in the period 2002-2010 (Eurostat 2012). In the UK, there are 950,000 SMEs that generate about $80 \%$ of the production cost of the UK construction industry (Robson et al. 2014). At the start of $2014,99.3 \%$ of the 5.2 million private sector businesses were small, and $99.9 \%$ were small or medium sized (Department for Business Innovation \& Skills 2014).
The differences between SMEs and large organisations are expressed in terms of resources limitation, and competitive and functional structure. Generally, SMEs usually lack personnel, finance and knowledge relevant to management and adopting new technology as well as effective strategies of development (Jutla et al. 2002; Caskey et al. 2001). SMEs usually find it difficult to tackle barriers and limitations when the industry requires its sectors to change in order to catch up with the developments and the requirements of the country (Eurostat 2012). Typically, the amount of large companies adopting BIM are almost threefold more than smaller ones, the former making up $74 \%$ in 2009 and this figure continuing to rise up to $91 \%$ in 2012, whereas BIM adoptions in small firms are just around $25 \%$ in 2009 , followed by small to medium firms which account for $41 \%$ (SmartMarket Report 2012).

Evidently, if BIM is to be the new methodology used by the industry to conduct construction projects then it has to accommodate all organisation sizes. However, the aforementioned figures indicate that adopting BIM amongst SMEs has, so far, not received enough attention by policy makers, the industry, and the research community. As a result, they have not fully recognised the benefits of using BIM in project delivery (Kouider 2013). This field of study has also attracted little attention, which is reflected in the limited number of publications that directly reference the use of BIM within SMEs. Consequently, it emerged that SMEs are pessimistic about BIM and consider BIM discriminates against small independent practices in the built environment sector, notwithstanding the fact that BIM implementation could be more easily achieved in comparison with larger organisations (NBS 2015).

Efforts to support BIM adoption amongst SMEs in the construction industry include the development of BIM support groups, standards and protocols. BIM4SME is responsible for providing resources, best practices and knowledge to SMEs to help them achieve BIM level 2 (Bim4sme.org). The BIM Protocol created by the Construction Institution Council in 2013 aims to clarify legal issues surrounding the obligations and rights of stakeholders on a BIM project (Bim4sme.org). The Public Available Specification (PAS) parts 2, 3 and BS1192-4 have been developed specifically for information management for the capital/delivery phase of construction, the operation phase of asset, and the exchange of information throughout the lifecycle of a facility (Bim4sme. org). In addition, a series of BIM frameworks has been developed to evaluate areas and to identify factors for practical BIM effectiveness (Jung et al. 2011) and multidisciplinary collaboration (Singh et al. 2011); optimising and simulating construction planning and scheduling (Song et al. 2012); identifying individual BIM competencies (Succar et al. 2013); and ensuring best value in construction projects (Liu et al. 2015). However, these frameworks and efforts have so far had little impact on SMEs adoption of BIM. 
It appears that the surge of research to increase BIM adoption has, so far, had limited success in convincing SMEs. This failure is largely due to the lack of understanding of the basic business case, which has led SMEs ignoring the BIM agenda. Kouider (2013) found that not knowing what value SMEs can achieve from their money investment and how long it will take to get a return on the investment are two of the main barriers for BIM adoption. Indeed, BIM is perceived by SMEs to disrupt their work process, as well as having a significant impact on already scarce human and financial resources. Consequently, its implementation has several accompanying risks. SMEs find it difficult to weigh up the risks and rewards that they may face when they invest in BIM (Kouider 2013; Chien et al. 2014). Amongst other concerns such as a lack of skills and BIM knowledge, SMEs seem worried about BIM affordability (Liu et al. 2010; Eastman et al. 2011; Migilinskas et al. 2013), and return on investment is uncertain (Yang et al. 2008; Azhar et al. 2011, 2012; Won et al. 2013). Despite various efforts and initiatives, a recent study conducted by NBS (2015) revealed that "BIM adoption is moving from being led by innovators and early adopters, towards being a more mature market, where the mainstream is investigating and assessing the benefits of doing so".
Unfortunately, there is currently a lack of guidance and assistance for SMEs in how to adopt BIM in project delivery. Absence of standards and frameworks to evaluate the extent to which BIM can bring benefits to AEC through project delivery, especially for the SMEs, results in low rates of BIM adoption (Liu et al. 2010; Eastman et al. 2011; Migilinskas et al. 2013; Kouider 2013). SMEs are known to be a hard to reach groups and require specific assistance to encourage BIM adoption.

This research harnessed advances in identifying the practicality of BIM effectiveness to increase its implementation. The analysis of recent efforts, outlined in Table 1, helped determine the key issues affecting BIM adoption. This paper reports on the development of a comprehensive framework designed to assist SMEs in brokering the potential risks and rewards of adopting BIM, especially in the context of project delivery.

\section{Conceptual framework to help in the analysis of the risks and rewards of adopting BIM for SMEs}

A two-step approach to select relevant articles to be included in the study was adopted. For the first step, it was decided to screen the literature to identify sources developing methodologies for frameworks for BIM adoption.

Table 1. Key factors affecting BIM adoption

\begin{tabular}{|c|c|c|c|c|c|c|c|c|c|c|c|}
\hline \multirow[b]{2}{*}{ Reference } & \multicolumn{3}{|c|}{ Involvement phase } & \multicolumn{3}{|c|}{ Project value } & \multicolumn{2}{|c|}{ Source of funding } & \multicolumn{3}{|c|}{ Procurement route } \\
\hline & 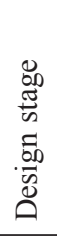 & 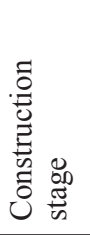 & 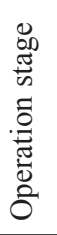 & $\begin{array}{l}\Xi \\
\qquad \begin{array}{l}n \\
+\infty \\
\vee\end{array}\end{array}$ & 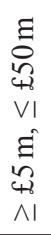 & $\begin{array}{l}\Xi \\
\vdots \\
0 \\
48 \\
\wedge 1\end{array}$ & $\frac{.0}{3}$ & 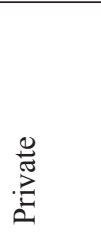 & 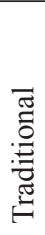 & 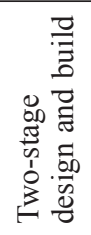 & 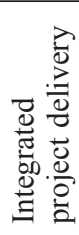 \\
\hline Al-Hammad et al. (1997) & $\mathrm{x}$ & $\mathrm{x}$ & $\mathrm{x}$ & & & & & & & & \\
\hline Bryde et al. (2013) & $\mathrm{x}$ & $\mathrm{x}$ & $\mathrm{x}$ & $\mathrm{x}$ & $\mathrm{x}$ & $\mathrm{x}$ & $\mathrm{x}$ & $\mathrm{x}$ & & & \\
\hline Negendahl (2015) & $\mathrm{x}$ & $\mathrm{x}$ & $\mathrm{x}$ & & & $\mathrm{x}$ & $\mathrm{x}$ & $\mathrm{x}$ & & & $\mathrm{x}$ \\
\hline Succar (2012) & $\mathrm{x}$ & $\mathrm{x}$ & $\mathrm{x}$ & & & & & & & & \\
\hline Arditi et al. (1999) & $\mathrm{x}$ & $\mathrm{x}$ & $\mathrm{x}$ & & & & & & & & \\
\hline Oti et al. (2015) & $\mathrm{x}$ & $\mathrm{x}$ & $\mathrm{x}$ & & & & & & & & \\
\hline Eastman et al. (2011) & & & & $\mathrm{x}$ & $\mathrm{x}$ & $\mathrm{x}$ & & & $\mathrm{x}$ & $\mathrm{x}$ & $\mathrm{x}$ \\
\hline Eadie et al. (2015) & & & & & & & & & $\mathrm{x}$ & $\mathrm{x}$ & $\mathrm{x}$ \\
\hline Luu et al. (2013) & & & & & & & & & $\mathrm{x}$ & $\mathrm{x}$ & $\mathrm{x}$ \\
\hline Volk et al. (2014) & & & & & & $\mathrm{x}$ & $\mathrm{x}$ & $\mathrm{x}$ & & & \\
\hline Liu et al. (2010) & & & & $\mathrm{x}$ & $\mathrm{x}$ & $\mathrm{x}$ & & & & & \\
\hline Azhar et al. (2011) & & & & $\mathrm{x}$ & $\mathrm{x}$ & $\mathrm{x}$ & & & & & \\
\hline Yang et al. (2008) & & & & $\mathrm{x}$ & $\mathrm{x}$ & $\mathrm{x}$ & & & & & \\
\hline Byrne et al. (2011) & & & & & & & & & $\mathrm{x}$ & $\mathrm{x}$ & $\mathrm{x}$ \\
\hline Cox et al. (2011) & & & & & & & & & $\mathrm{x}$ & $\mathrm{x}$ & $\mathrm{x}$ \\
\hline Hogg et al. (2007) & & & & & & & & & $\mathrm{x}$ & $\mathrm{x}$ & $\mathrm{x}$ \\
\hline Hughes et al. (2006) & & & & & & & & & $\mathrm{x}$ & $\mathrm{x}$ & $\mathrm{x}$ \\
\hline Migilinskas et al. (2013) & & & & $\mathrm{x}$ & $\mathrm{x}$ & $\mathrm{x}$ & & & & & \\
\hline Won et al. (2013) & & & & $\mathrm{x}$ & $\mathrm{x}$ & $\mathrm{x}$ & & & & & \\
\hline
\end{tabular}


A total of 226 citations were identified through the online database search. Articles not addressing the research focus were excluded. Those meeting the inclusion criteria were retrieved in full. The literature once extracted was critically appraised and discussed. A narrative approach was then selected to synthesise the data.

The final studies were scrutinised and nineteen articles were identified. A systematic literature review of these studies established a link between BIM adoption and involvement stage, project value, source of funding, as well as procurement route (Table 1). For each main component, a series of attributes were also identified. These factors paved the way to the development of the conceptual framework.

\subsection{Involvement phase}

The involvement phase refers to the timing of the engagement in project delivery in order to allow an SME to maximise rewards and minimise risks when adopting BIM to deliver projects (Al-Hammad et al. 1997; Negendahl 2015; Succar 2012). The involvement phase of project delivery is divided into three stages: design stage, construction stage, and operation stage.

The design stage is a combination of strategic decision making, preparation and brief, concept design, and technical design. This is considered as the most important stage of project delivery because decision making, assigning resources to parties, and allocating risks and rewards are made during this phase (Penttilä et al. 2007; Abrishami et al. 2014; Bryde et al. 2013; Negendahl 2015; Succar 2012). It is recognised that the involvement of key disciplines at the early stages of the project result in optimum benefits for project delivery (Lahdenperä 2012).

The construction stage is where contractors complete operations according to the conditions of the contract. It is the stage when work starts on site and visible progress is made (Fewings 2013). The process of coordinating human resources, materials, and machines is deployed at this stage (Li et al. 2012). The operation stage refers to the handover of the building and conclusion of the building contract. Undertaking of maintenance work in accordance with the schedule of services is assigned to this stage (Becerik-Gerber et al. 2011). Parties' involvement at the construction and maintenance/operation stages has less influence on project quality and outcomes as key decisions are taken at earlier stages of the process.

\subsection{Project value}

The construction industry is experiencing a major change towards projects of increasing complexity (Naoum 2003). Project's values vary from less than $£ 5 \mathrm{~m}$ for small projects, to $£ 5-£ 50 \mathrm{~m}$ for medium projects, and more than $£ 50 \mathrm{~m}$ for large projects. Procurement choice is dependent on the complexity or size of projects, and aims to ensure completion on time and within budget (CIOB 2010). According to NBS (2015), small sized projects are associ- ated with organisations which are slower in adopting new technology and have fewer staff compared to larger ones. This type of organisation struggles to win business especially in the current highly competitive environment. Medium sized projects are usually derived from a breakdown of complex projects, which are delivered by groups of SMEs. Each SME can be assigned a suitable unit of the project with a tight schedule of performance (Hatmoko et al. 2010). Thus, managing the collaborative performance of SMEs in conducting medium sized projects is significant. Similarly, managing parties participating in large sized projects also needs to be considered carefully. The general rule is that the larger the scope of the project, the more complex the participants will be (Volk et al. 2014). There has been an assumption that using BIM on small scale projects (e.g. less than $£ 5 \mathrm{~m}$ ) could be less likely to yield the level of benefit compared to projects of a larger scale (Bryde et al. 2013).

\subsection{Source of funding}

Project funding is sourced from either the public or private sector (Jaafar et al. 2012). Private clients are characterised by being increasingly better informed, more aware and more knowledgeable about how to get into the building process (SmartMarket Report 2014). They tend to expect best value from contractors and suppliers. This has led to a shift from "lowest-price wins" to "multi-criteria selection practices" in the contractor selection process, especially since the implementation of BIM (Wong et al. 2010). The public sector client, primarily the government, is observed to be the initiator of major developments in social amenity projects. It is involved in the construction of buildings such as schools and colleges, hospitals, universities, fire stations, prisons and museums (Office for National Statistics 2014). This sector is considered the main driver of the BIM agenda (British Standards Institution 2013). However, there is evidence to suggest that private clients are increasingly interested in BIM (SmartMarket Report 2014).

\subsection{Procurement route}

Procurement in construction projects is defined as a process whereby clients make decisions about how they will build (Hogg et al. 2007). The procurement stage plays a significant role in contributing to the success of any building project (Squires et al. 2011). Essentially, construction procurement is an array of considered risks that need to be examined carefully by stakeholders. Each procurement route has developed its own characteristics to suit different kinds and sizes of project (Nahapeit et al. 1985). As a general rule, the traditional procurement method is most suited for delivering small sized projects whereas design and build is used for projects with medium size, and integrated project delivery (IPD) is for large and complex projects (CIOB 2010). In traditional procurement, the client appoints consultants to design the project in detail. The tender documents are then prepared, includ- 
ing drawings, work schedules, and bills of quantities. Constructors are then invited to submit tenders for the construction of the project (Hogg 2007). The two stage design and build method was developed to eliminate the liability gap between design and construction within the traditional method. The client benefits from single point responsibility by making the contractors solely responsible for design, construction and solving problems during the building lifecycle (Franks 1998; Masterman 2002). Integrated Project Delivery (IPD) advocates the early involvement of key parties (Lahdenperä 2012). IPD seeks to improve construction productivity by using a combination of partnering concepts and lean thinking to improve communication, eliminate waste, reduce costs, address expectations and generate value for all parties involved (Hardin 2009). IPD achieves significant improvements in six performance areas: quality, schedule, project changes, communication among stakeholders, environmental, and financial performance (Asmar et al. 2013).

\subsection{Conceptual framework for BIM adoption by SMEs}

Frameworks are developed to assist and guide research effort, enhance exchanging information or knowledge, and to consolidate relevant concepts into a descriptive or predictive model (Jung et al. 2011; Kirs et al. 1989). There has been no systematic effort to date to bring together the results of research in SMEs' BIM adoption. Consequently, this paper seeks to bridge this gap and provide a conceptual framework to give a theoretical foundation to the study of brokering risks and rewards in the adoption of BIM for project delivery.

Notwithstanding the proliferation of literature examined, no studies attempted to develop a framework that postulated criteria for brokering risks and rewards, associated with BIM adoption for project delivery by SMEs (see Table 1). The recent and increasingly widespread use of BIM in the construction industry (Shepherd 2004) and the lack of engagement of SMEs (Federation of Master
Builders 2013) with a BIM agenda have created a need to develop a conceptual model. The model then requires testing to ascertain if the prevailing assumptions can form the basis for the development of an accepted theory in the field.

The conceptual framework of this study is illustrated in Figure 1 was established based on key factors (Table 1) synthesised from existing literature in this field to address the gap in knowledge. It outlines the entire context that SMEs are considering when they adopt BIM to deliver construction projects. It emerges that there are four broad issues in the study of BIM adoption that have impact on SMEs:

1. Involvement phase, which includes design stage, construction stage, and operation /maintenance stage.

2. Project value, which consists of projects less than $£ 5$ million, between $£ 5$ million and $£ 50$ million, and greater than $£ 50$ million.

3. Source of funding, which is concerned with projects funded by either public or private clients.

4. Procurement route, which deals with traditional method, two-stage design and build, and integrated project delivery.

In addition, the risks and the rewards associated with each criterion are also synthesised from existing literature and are stored in the risk and reward profiles. They are then used to determine the potential risks and rewards linked to each criterion. Depending on users' selection, different risks and rewards are generated, thus providing an informed basis for decision-making on the best course of action for BIM adoption. These potential risks and rewards are assessed in terms of their likelihood of occurrence and level of impact on an SME. To ensure improved accessibility, the framework is presented to SMEs online through a friendly user interface. The advantage of this method is its ease of use, enhanced accessibility, and attractive presentation.

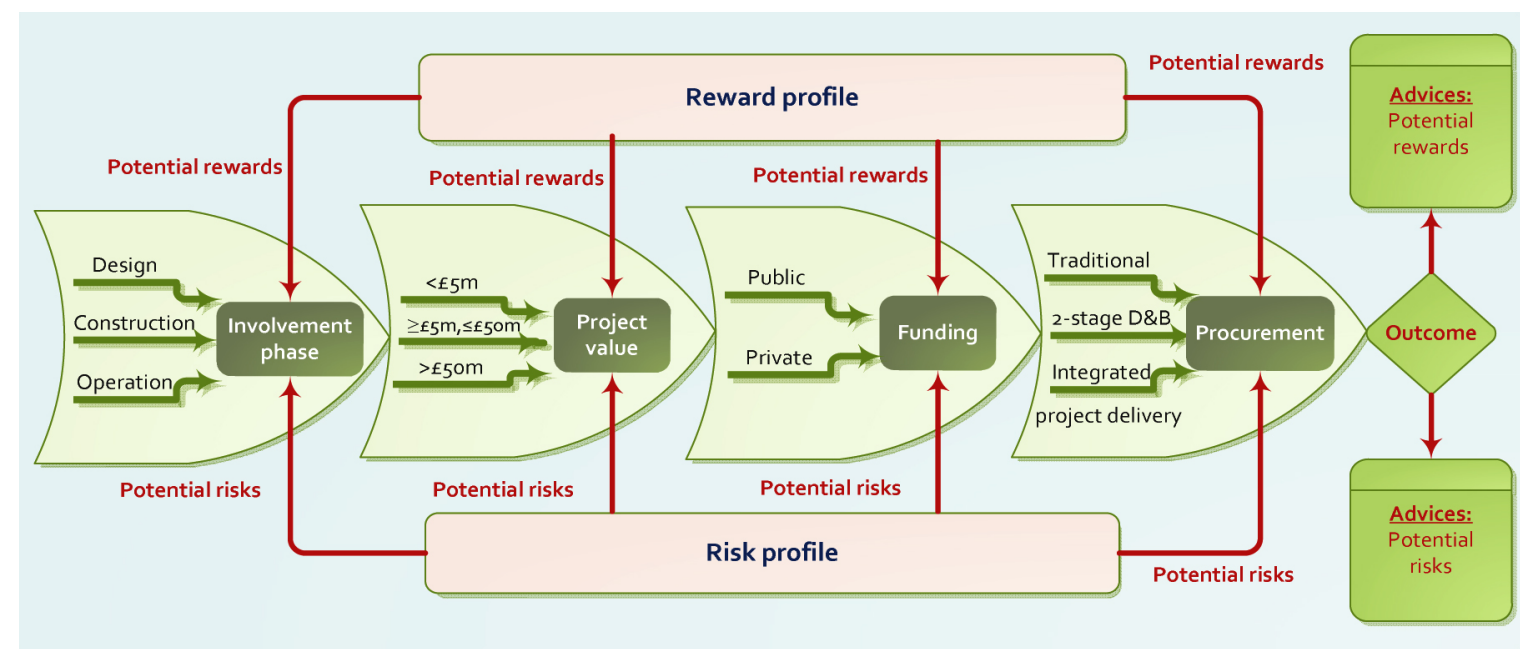

Fig. 1. Conceptual framework to help in the analysis of the risks and rewards of adopting BIM for SMEs 


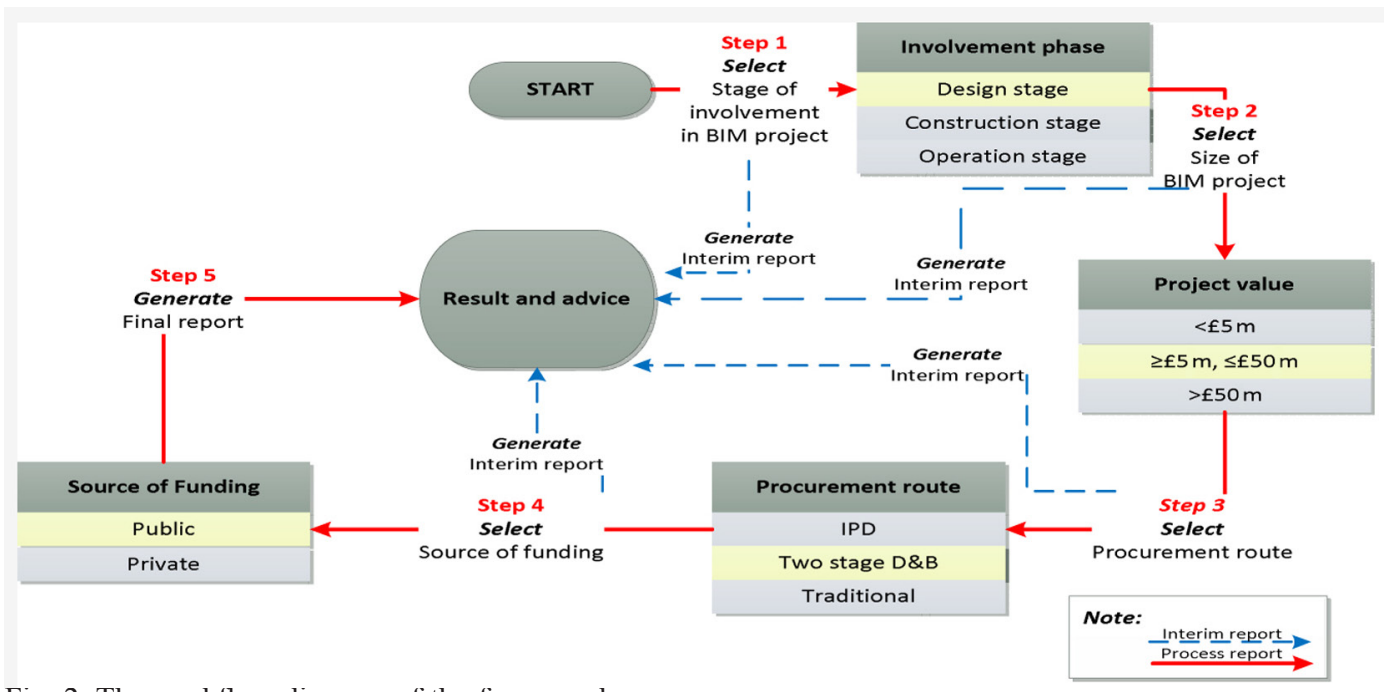

Fig. 2. The workflow diagram of the framework

The workflow diagram of the framework is illustrated in Figure 2. It shows that there are a total of five steps that are used to anticipate the risks and opportunities involved in using BIM in project delivery. These steps start with identifying the involvement phase (e.g. design stage). The framework then deals with the project value (e.g. $\geq £ 5 \mathrm{~m} \leq £ 50 \mathrm{~m}$ ), the procurement route (e.g. two stage D\&B), as well as the source of funding (e.g. Public) as criteria to generate a final recommendation at the end of the assessment process. The process of these steps is demonstrated in Figure 2. The framework also allows SME users to generate interim reports at each step of the process. These reports include presenting risks and rewards at every step of the process (indicated by dash lines). The risks and rewards are calculated based on the weight of the criteria. Risks and rewards associated with the criteria were also validated and then used as informative output in the final report of the assessment process.

\section{Research methodology}

The primary research method in this study uses a process of activities known as framework validation. Framework validation entails checking that the system complies with its own requirements and is free from failures or incorrect behaviour (Ferreira et al. 2009). This process is conducted by obtaining objective evidence establishing that the system will perform its intended functions. Consequently, the validation of the conceptual framework helps to deter- mine the level of robustness and usefulness of the criteria for SMEs to enable them to maximise the benefits and minimise the potential risks.

An initial pilot study was conducted with six SMEs as a precursor to the validation of the framework. The purpose of this pilot study was to ensure that the evaluation of each criterion of the framework was meaningful and easy to follow. Feedback led to adjustments to the criteria and the design of the framework. Subsequently, an online structured questionnaire survey was deployed for the validation of the criteria of the framework. The survey sought to examine the impact of each attribute, within the framework, on SME organisations, in terms of their potential risks and rewards.

Rank order questions were selected for this survey, using Qualtrics platform which provides an individual token system for survey management. This ensures that participants cannot undertake the survey twice and all data is stored in an online MySQL data base. The rank order question type allows participants to rank a set of items against each other. This type of question has the benefit of requiring respondents to identify how elements or choices compare to each other and determine the most important ones to participants (Cao et al. 2015). Figure 3 illustrates how respondents had the opportunity to classify the criteria from the most to the least important by dragging and dropping the available choices into an appropriate order. They were asked to rank between elements within a situation to ascertain the most and the

Q10. Please rank the following stages of involvement in project delivery from the most to the least likely to allow an SME to maximise the benefits and minimise the risks when adopting BIM

\begin{tabular}{l|l|}
\hline Design stage & 1 \\
\hline Construction stage & 2 \\
\hline Operation/maintenance stage & 3 \\
\hline
\end{tabular}

Fig. 3. Sample of ranked questions by a respondent 
least important attributes in terms of the likelihood of occurrences and impacts of BIM implementation in project delivery. The survey included five sections which is detailed in Table 2 below.

Participants in the survey were limited to companies with BIM experience, working in the UK, and were largely selected from the main BIM groups on LinkedIn. These include BIM4SME ( 857 members), BIM Architecture (18,214 members), and BIM Experts (41,281 members). To determine the sample size, Czaja et al. (1996) suggest that sample size ss could be calculated by using the following formula:

$$
s s=\frac{Z^{2} * \mathrm{e}(1-e)}{c^{2}},
$$

where:

$z$ : Z score: 1.96 - the most common confidence intervals;

c: $10 \%$ - confidence interval, expressed as a decimal;

e: $50 \%$ - the worst case percentage picking choice, expressed as a decimal.

As a result:

$$
s s=\frac{z^{2} * e(1-e)}{c^{2}}=\frac{1.96^{2} * 0.5(1-0.5)}{0.1^{2}}=96.04 .
$$

However, there are currently 950,000 SMEs in the UK construction industry (House of Commons 2015), so the new sample size should be:

$$
\text { new } s s=\frac{s s}{1+\frac{s s-1}{p o p}}=\frac{96.04}{1+\frac{96.04-1}{950.000}}=96.03 \text {. }
$$

This result suggests that 96 responses are needed for a valid sample size.

To cater for a poor response rate, $20-30 \%$ above the sample size is believed to be the norm (Takim et al. 2004). Therefore, the sample size of this survey is determined as follows:

$$
s s=\frac{96.03}{0.2}=480 \text { participants. }
$$

An invitation letter with a link to the online survey included was sent to 480 personal emails in the UK, selected carefully from the aforementioned BIM groups. Before the survey went live, three pilots and two semistructured interviews were conducted with personnel with BIM experience to ensure the content of the questionnaire and the uniform understanding of the research issues were obtained. As a result of the invitation to be involved in the survey, 115 participants responded positively. However, only 93 participants completed all the questions in the survey.

\subsection{Data analysis methodology}

This research adopted the voting analytic hierarchy process (VAHP) methodology developed by Hadi-Vencheh and Niazi-Motlagh (2011) to calculate the weight and rank elements of the issues being investigated. This model is inherited from the analytic hierarchy process (AHP), which is popular for multiple criteria decision making in systems involving many levels and the use of the theory of measurement through pair-wise comparisons (Marjanavie et al. 2010). In this method, Hadi-Vencheh and Niazi-Motlagh (2011) proposed a formula to calculate the weight of elements independently from the total number of responses and the scale of ranking. The weight of every element is calculated based on the number of elements and the number ranks (votes) in each order (place). This model is matched to the purpose of the research as ranking between elements from the most important to the least important and the number of elements varies depending on the issues being invested. The voting and ranking model is as follows:

$$
\begin{gathered}
\partial_{r r}=\max \sum_{s=1}^{s} x_{r s} w_{s} ; \\
\sum_{s=1}^{s} x_{r s} w_{s} \leq 1 \quad r=1,2, \ldots S ; \\
w_{1} \geq 2 w_{2} \geq 3 w_{3} \geq \ldots \geq 0 ; \\
\sum_{s=1}^{s} w_{s}=1,
\end{gathered}
$$

\begin{tabular}{|c|c|c|}
\hline Section & Assessment criteria & Task \\
\hline 1. Personal information & $\begin{array}{l}\text { Role within their organisation; Length of } \\
\text { professional experience; Length of BIM experience; } \\
\text { Size of organisation that they are working for. }\end{array}$ & \multirow{5}{*}{$\begin{array}{l}\text { In section } 1 \text {, the participants were asked } \\
\text { to provide their personal information. In } \\
\text { each section from } 2 \text { to } 5 \text {, they were asked } \\
\text { to rank between elements, from the most to } \\
\text { the least likely, to allow SMEs to maximise } \\
\text { the benefits and minimise the risks when } \\
\text { adopting BIM. In addition, they were } \\
\text { also required to rank the risks and rewards } \\
\text { associated with each item, from the most to } \\
\text { the least likely, in terms of their likelihood of } \\
\text { occurrence and level of impact on an SME. }\end{array}$} \\
\hline 2. Stages of involvement & $\begin{array}{l}\text { Design stage; Construction stage; Operation/ } \\
\text { maintenance stage. }\end{array}$ & \\
\hline 3. Project value & $\begin{array}{l}\text { Less than } £ 5 \text { million; Between } £ 5 \text { million and } £ 50 \\
\text { million; Greater than } £ 50 \text { million. }\end{array}$ & \\
\hline 4. Source of funding & Pubic funded project; Private funded project. & \\
\hline 5. Procurement route & $\begin{array}{l}\text { Traditional; Two-stage design and build; Integrated } \\
\text { project delivery. }\end{array}$ & \\
\hline
\end{tabular}

Table 2. Details of survey design 
where $x_{r s}$ is the total votes of the $r^{\text {th }}$ element for the $s^{\text {th }}$ place. In this survey, $r$ equal to $s$ is also the number of elements within an issue of investigation. $w_{s}$ is the constraint standing for the difference in weight between $s^{\text {th }}$ and $(s+1)^{\text {th }}$ place. The successive steps to analyse the data are as follows:

Step 1 - calculate $w_{s}$. For example, the involvement phase in the framework of this study consists of three sub-criteria: Design stage, Construction stage and Operation stage. Therefore, by using the Eqn (3):

$$
w_{1} \geq 2 w_{2} \geq 3 w_{3} \geq 0
$$

and

$$
\sum_{s=1}^{s} w_{s}=1
$$

As a result, $w_{s}$ will be: $w_{1}=0.545455 ; w_{2}=0.272727$; $w_{3}=0.181818$.

Step 2 - calculate the weight and rank criteria by using the VAHP formula (2): $\partial_{r r}=\max \sum_{s=1}^{s} x_{r s} w_{s}$.

The result of this process can be seen in Table 3 .

Table 3. Priority votes of 3 criteria from 93 respondents in the survey

\begin{tabular}{lcccccc}
\hline \multicolumn{1}{c}{ Criteria } & 1st & 2nd & 3rd & Weight & Normal & Rank \\
\hline Design & 64 & 11 & 18 & 41.182 & 0.443 & 1 \\
Construction & 15 & 69 & 9 & 28.636 & 0.308 & 2 \\
Operation & 14 & 13 & 66 & 23.182 & 0.249 & 3 \\
Total & 93 & 93 & 93 & 93 & 1 & \\
\hline
\end{tabular}

Consequently, based on the scale of ranking, the VAHP method has helped to determine the weight for each criterion. The weights were subsequently normalised and then ranked. Similarly, this process of calculation is applied to all the other criteria of the framework.

\section{Results and discussion of the validation of the framework}

A total of 93 participants responded to the survey, which amounts to $96.8 \%$ of the target (96 responses). Participants of the survey are working for different types of organisation ranging from micro (less than 10 staff) to large (greater than 250 staff). This sample selection was expected to achieve a full range of views on BIM in terms of risks and rewards, when adopting it to deliver construction projects. The sample breakdown is shown in Table 4 and the size of organisation is defined by the European Union criteria (European Commission 2015).

As expected, the survey revealed that the majority of the organisations that have adopted BIM in project delivery are large organisations (33.33\%). It can be inferred that these types of organisations are more likely to be getting ready to achieve BIM adoption at level 2 by 2016 . Furthermore, a large number of participants, accounting for the second highest responses $(27.96 \%)$ in the survey, are working for micro organisations, across the UK.

Table 4. Organisation size from sample

\begin{tabular}{lccc}
\hline Organisation size & Number & $\begin{array}{c}\text { Percentage of } \\
\text { respondents }\end{array}$ & $\begin{array}{c}\text { Cumulative } \\
\%\end{array}$ \\
\hline $1-10$ (micro) & 26 & $27.96 \%$ & $27.83 \%$ \\
$11-50$ (small) & 19 & $20.43 \%$ & $48.39 \%$ \\
$51-250$ (medium) & 17 & $18.28 \%$ & $66.67 \%$ \\
$>250$ (large) & 31 & $33.33 \%$ & \\
Total & 93 & 100 & 100 \\
\hline
\end{tabular}

A large number of participants, accounting for the second highest responses (27.96\%) in the survey, are working for micro organisations, across the UK. Despite the larger participation amongst SMEs, the results revealed that the majority of the organisations that have adopted BIM in project delivery are large companies $(33.33 \%)$. This is in agreement with previous studies revealed that these types of organisations are more likely to be getting ready to adopt BIM (NBS 2015). Indeed, large gaps amongst organisations in terms of BIM adoption was found, and the large one is still dominant (Electrical Contractor Association 2015).

The respondents represented many professions within the construction industry, as indicated in Table 5. They were asked to list the professional duties that they are carrying out for their company. The professional experience and BIM experience of participants was highly relevant, as detailed in Table 6 . The experience of the respondents is to ensure knowledge and experience of participants within the issues under investigation and the validity of collected data. The results showed that more than $70 \%$ of participants had more than four years of experience in the construction industry, and about 55\% had more than four years of working with BIM in project delivery (Table 6). It seems that there is an increasing trend for professionals

Table 5. Sample breakdown by professional duties

\begin{tabular}{lcc}
\hline Professional duties & Frequency & $\begin{array}{c}\text { Percentage of } \\
\text { respondents }\end{array}$ \\
\hline Architecture & 18 & $19.35 \%$ \\
BIM manager & 15 & $16.13 \%$ \\
Quality surveyor & 12 & $12.9 \%$ \\
BIM professional & 10 & $10.75 \%$ \\
BIM coordinator & 9 & $9.68 \%$ \\
BIM technician & 7 & $7.53 \%$ \\
BIM consultant & 6 & $6.45 \%$ \\
specialist & 4 & $4.3 \%$ \\
Civil engineer & 4 & $4.3 \%$ \\
Structural engineer & 1 & $1.08 \%$ \\
Construction & & \\
designer & & \\
\hline
\end{tabular}


to have BIM experience in accordance with the growth in BIM adoption. This finding concurs with the SmartMarket Report (2014), which revealed that the number of organisations with five and more years' experience in BIM use doubled between 2009 and 2012: from $6 \%$ to $13 \%$ for those with five years' experience, and from $18 \%$ to $36 \%$ for those with more than 5 years' experience. Indeed, an investment in upskilling staff in BIM is increasingly seen as critical as it enables organisation to have more competencies to compete with other rivals (Fewings 2013).

Table 6. Experience of participants

\begin{tabular}{lcccc}
\hline \multirow{2}{*}{$\begin{array}{c}\text { Years of } \\
\text { experience }\end{array}$} & \multicolumn{2}{c}{$\begin{array}{c}\text { Professional } \\
\text { experience }\end{array}$} & \multicolumn{2}{c}{ BIM experience } \\
\cline { 2 - 5 } & Number $\begin{array}{c}\% \text { of } \\
\text { respondents }\end{array}$ & Number & $\begin{array}{c}\% \text { of } \\
\text { respondents }\end{array}$ \\
\hline $1-3$ years & 27 & $29.03 \%$ & 41 & $44.09 \%$ \\
$4-10$ years & 31 & $33.33 \%$ & 45 & $48.39 \%$ \\
$>10$ years & 35 & $37.63 \%$ & 7 & $7.53 \%$ \\
\hline
\end{tabular}

\subsection{Stages of involvement}

Respondents were asked to rank the stage of involvement in projects from the most to the least likelihood of occurrence. The results in Table 7 indicate that the design stage is ranked as the best stage with the weight of 0.443 . This is followed by the construction stage and the operation stage, occupying the weight of 0.308 and 0.249 respectively.

Table 7. Stages of involvement that allow an SME to maximise rewards and minimise risks

\begin{tabular}{lcccccc}
\hline \multicolumn{1}{c}{ Criteria } & 1st & 2nd & 3rd & Weight & Normal & Rank \\
\hline Design & 64 & 11 & 18 & 41.182 & 0.443 & 1 \\
Construction & 15 & 69 & 9 & 28.636 & 0.308 & 2 \\
Operation & 14 & 13 & 66 & 23.182 & 0.249 & 3 \\
Total & 93 & 93 & 93 & 93 & 1 & \\
\hline
\end{tabular}

The findings show that the SMEs who usually participate in the early stage of project involvement are likely to get more opportunities to maximise rewards and minimise risks. This trend is downward, reaching the lowest point in terms of benefits and the highest level of risks in the events of organisations participating in projects tardily. This can be explained by the phenomenon that critical decisions have been taken in the early stages of the project. Lahdenperä (2012) found that the later decisions are made, the more expensive the design changes are. The findings of this study confirm previous research that by starting in very early stages of the project, stakeholders are more likely to see the benefits of BIM such as enhancing coordination, productivity, and business operations (Light 2011). Indeed, early involvement means higher chance to minimize waste and increase value through visualising model, which can help to avoid errors and omissions (Azhar et al. 2012). By doing so, any errors, omissions, risks can be identified and mitigated early. This can help parties obtain significant waste reduction across the whole project (Azhar et al. 2011). In addition, high collaborative working in the early stages of the project can lead to more time for managing and predicting implications on construction, maintenance and operations, and as a result, project performance can be improved dramatically (MacLeamy 2004).

\subsection{Project values}

In terms of project value, the participants were asked to rank types of project value from most to least in terms of enabling for SMEs to maximise rewards and minimise risks when using BIM to deliver BIM projects. The survey shows that the best project value for BIM is between $£ 5$ million and $£ 50$ million, closely followed by projects greater than $£ 50$ million and less than $£ 5$ million (Table 8). The difference in terms of weight between elements is 0.028 , when comparing the first ranked element to the second one, and 0.003 for the difference between the second ranked item and the lowest ranked one.

The result of this study demonstrated that whatever the project value is, BIM is potentially beneficial. It suggests that BIM could be relevant to various project values, including humbler projects-less than $£ 5 \mathrm{~m}$ in value. This finding challenges the prevailing assumption that we should not bother with BIM for small-scale projects (i.e. NBS 2015; Bryde et al. 2013). Indeed, research found that BIM is applicable to projects of all scales, and it is useful in assisting organisations to build small as well as highrisk projects successfully (Furneaux et al. 2008). However, industry currently perceives the prime added value of BIM is in managing large and complex projects, where failures in communication are more likely. Therefore, BIM is seen as essential in addressing the various challenges, such as clash detection, schedules and communication (Azhar et al. 2011). This attitude often resulted in ignoring BIM adoption in the context of a lower project value. Levy (2012) argued that smaller projects are also

Table 8. Value of project that allows an SME to maximise rewards and minimise risks

\begin{tabular}{lcccccc}
\hline Criteria & 1 st & 2nd & 3rd & Weight & Normal & Rank \\
\hline Between $£ 5$ million and $£ 50$ million & 27 & 60 & 2 & 31.455 & 0.353 & 1 \\
Greater than $£ 50$ million & 31 & 16 & 42 & 28.909 & 0.325 & 2 \\
Less than $£ 5$ million & 31 & 13 & 45 & 28.636 & 0.322 & 3 \\
Total & 89 & 89 & 89 & 89 & 1 & \\
\hline
\end{tabular}


vulnerable to erroneous quantitative analysis, and therefore BIM is more critical as these types of buildings "tend to have smaller budget margins, and even a small error may lead to project damaging cost overruns".

\subsection{Source of funding}

Essentially, public and private clients are the main sources of funding for construction projects. For this question, participants were asked to rank whether public or private sector is the potential sector that allow them to maximize the benefits and minimize the risks in adopting BIM. Results presented in Table 9 show that both private and public source of funding are significant, as they are respectively closely related $(0.51$ and 0.49$)$. This result concurs with a recent findings, which indicates that around two thirds of both public sector (65\%) and private sector (70\%) UK clients require now BIM on new projects they will be starting (SmartMarket Report 2014).

Table 9. Sources of funding that allow an SME to maximise rewards and minimise risks

\begin{tabular}{lccccc}
\hline \multicolumn{1}{c}{ Criteria } & 1st & 2nd & Weight & Normal & Rank \\
\hline $\begin{array}{l}\text { Private funded } \\
\text { projects }\end{array}$ & 45 & 40 & 43.329 & 0.51 & 1 \\
$\begin{array}{l}\text { Public funded } \\
\text { projects }\end{array}$ & 40 & 45 & 41.671 & 0.49 & 2 \\
Total & 85 & 85 & 85 & 1 & \\
\hline
\end{tabular}

The current trend of adopting BIM for project delivery is not only affecting public clients (British Standards Institution 2013), but they are also required by the private sector. This finding is fundamental in encouraging SMEs to invest BIM in their organisations to be able to win public projects, as they are currently relying heavily on private projects where a BIM mandate has not been applied yet. Blackwell (2012) warns SMEs against slow uptake of BIM, leading to a loss of contracts in both the domestic and international markets. Above all, this trend may worsen their rate of success in winning bids for public sector contracts (Federation of Master Builders 2013). Furthermore, the findings of this study is urging for new strategies by SMEs to adopt BIM technology and collaborative practices to be able to win both public and private projects in an increasingly competitive market.

\subsection{Procurement routes}

In the construction industry, procurement routes are considered as the backbone in terms of the process of project delivery. A selection of an appropriate procurement route could reduce project cost dramatically and enhance the probability of project success (Gordon 1994; Luu et al. 2005). Consequently, when making decisions about whether to adopt BIM in project delivery or not, a consideration of procurement routes cannot be ignored. In this survey, participants were asked to rank three kinds of procurement routes, presented in Table 10. The question required respondents to rank the potential that organisations can see in terms of maximising the rewards and minimising the risks when adopting BIM to deliver construction project, according to the different types of procurement route.

Table 10. Procurement routes that allow an SME to maximise benefits and minimise risks when adopting BIM

\begin{tabular}{lcccccc}
\hline Criteria & 1st & 2nd & 3rd & Weight & Normal & Rank \\
\hline $\begin{array}{l}\text { Integrated } \\
\text { project delivery }\end{array}$ & 61 & 5 & 19 & 38.091 & 0.448 & 1 \\
$\begin{array}{l}\text { Two-stage } \\
\text { design and build }\end{array}$ & 17 & 50 & 18 & 26.182 & 0.308 & 2 \\
$\begin{array}{l}\text { Traditional } \\
\text { Total }\end{array}$ & 7 & 31 & 47 & 20.818 & 0.245 & 3 \\
\hline
\end{tabular}

The findings indicated in Table 9 show that the integrated project delivery procurement route is the best method to conduct BIM projects (0.448), followed by two-stage design and build, and traditional procurement with the weight of 0.308 and 0.245 respectively. This finding supports the assumption that BIM together with the integrated project delivery procurement method can help organisations to improve communication, eliminate waste, reduce costs, address expectations and generate value for all parties involved in projects (Hardin 2009; Asmar et al. 2013). There is currently a large gap between the highest and the lowest element of investigation with the weight of 0.203 . Moreover, traditional procurement is considered as the most popular method and widely used by SMEs to deliver projects (The Chartered Institution of Building 2010). As such, this result provides a useful reminder to SMEs when they make decisions about adopting BIM to implement construction projects. The risks and rewards associated with procurement methods may vary greatly and SMEs need to consider this carefully.

\section{Conclusions}

This paper has proposed a conceptual framework to assist with the brokering of risks and rewards in adopting BIM in construction project delivery. Four key criteria were identified namely: involvement phase, project value, source of funding and procurement route. This conceptual model was validated by 93 participants from UK companies using BIM.

The validation of the framework revealed the four most significant factors that are able to help SMEs to maximise the benefits and minimise the risks in adopting BIM to deliver construction projects. (1) The most significant phase to participate in BIM projects is the design phase. This stage is identified as the essential stage in which all the key decisions are taken. Early involvement in BIM projects is critical to maximise the rewards and minimise the risks. Stakeholders must use the opportunity to influence key decisions that have significant impact on projects during construction, and maintenance/operations. (2) Regardless of project value, BIM is seen as beneficial 
in any case. Although projects valued between $£ 5$ million and $£ 50$ million seem the best choice for optimum BIM benefits, the gap between this type of project compared to other groups is very small with the difference of 0.028 and 0.003 in terms of weight, compared to second ranked and lowest ranked respectively. This finding is meaningful in encouraging and enhancing organisations working on different types of projects to invest in BIM in their organisations. (3) Private clients remain the main sector that SMEs need to pay attention to when conducting BIM projects. The traditional close relationship between SMEs and private clients is changing. This is mainly because the demand from private clients in BIM implementation has increased in recent years, whereas SMEs are still slow in investing in BIM. (4) SMEs should pay particular attention where traditional procurement is used as the most popular method of deploying BIM projects. The study shows that this kind of method is the least beneficial for BIM compared to its counterparts, which accounts for the weight of 0.245 . The highest ranked method is the integrated project delivery procurement route, which occupies 0.448 in terms of weight. Therefore, the risks and rewards of using BIM to conduct construction projects under the traditional procurement method may be questionable. SMEs need to carefully consider alternative procurement routes before investing in BIM for their organisation.

Future work includes the development of an online decision support system (DSS) to assist SMES in brokering the risks and rewards of adopting BIM in project delivery. The DSS is designed based on the results of the validated framework. It helps SMEs to identify the most and the least important likelihood of occurrences and the impacts of alternatives on their organisation when adopting BIM to deliver construction project. In addition, rewards and risks associated with criteria, which are stored in risk and reward profile, are also used to clarify selected alternatives. The DSS is built using HTML5, $\mathrm{PhP}$, and AJAX, together with the high security database management system MySQL. In addition, it is designed as an online tool which helps to increase the accessibility as well as the simplicity of dissemination to SMEs. A representative sample of SMEs will be selected for trialling and validating the DSS.

\section{References}

Abrishami, S.; Goulding, J.; Rahimian, F. P.; Ganah, A.; Sawhney, A. 2014. G-BIM framework and development process for integrated AEC design automation, Procedia Engineering 85: 10-17. https://doi.org/10.1016/j.proeng.2014.10.523

Al-Hammad, A.; Assaf, S.; Al-Shihah, M. 1997. The effect of faulty design on building maintenance, Journal of Quality in Maintenance Engineering 3(1): 29-39. https://doi.org/10.1108/13552519710161526

Arditi, D.; Nawakorawit, M. 1999. Designing buildings for maintenance: designers' perspective, Journal of Architectural Engineering 5(4): 107-116.

https://doi.org/10.1061/(ASCE)1076-0431(1999)5:4(107)
Asmar, E.; Hanna, M. A. S.; Loh, W. Y. 2013. Quantifying performance for the integrated project delivery system as compared to established delivery systems, Journal of Construction Engineering and Management 139(11). https://doi.org/10.1061/(ASCE)CO.1943-7862.0000744

Azhar, S.; Carlton, A.; Olsen, D.; Ahmad, I. 2011. Building information modeling for sustainable design and LEEDÂ ${ }^{\circledR}$ rating analysis, Automation in Construction 20(2): 217224. https://doi.org/10.1016/j.autcon.2010.09.019

Azhar, S.; Khalfan, M.; Maqsood, T. 2012. Building information modelling (BIM): Now and beyond, Australian Journal of Construction Economics and Building 12(4): 15-28. https://doi.org/10.5130/ajceb.v12i4.3032

Becerik-Gerber, B.; Jazizadeh, F.; Li, N.; Calis, G. 2011. Application areas and data requirements for BIM-enabled facilities management, Journal of Construction Engineering and Management 138(3): 431-442. https://doi.org/10.1061/(ASCE)CO.1943-7862.0000433

Blackwell, B. 2012. Industrial strategy: Government and industry in partnership - Building Information Modelling. HM Government.

British Standards Institution. 2013 [online], [cited 25 Nov 2015]. Available from Internet: https://www.bsigroup.com/

Bryde, D.; Broquetas, M.; Volm, J. M. 2013. The project benefits of building information modelling (BIM), International Journal of Project Management 31(7): 971-980. https://doi.org/10.1016/j.ijproman.2012.12.001

Byrne, J.; Fenton, M.; Hemberg, E.; McDermott, J.; O’Neill, M.; Shotton, E.; Nally, C. 2011. Combining structural analysis and multi-objective criteria for evolutionary architectural design, Applications of Evolutionary Computation, 204-213.

Cao, C.; Ai, H. 2015. Adaptive ranking of perceptual aesthetics, Signal Processing: Image Communication 39(C): 517-526. https://doi.org/10.1016/j.image.2015.09.003

Caskey, K. R.; Hunt, I.; Browne, J. 2001. Enabling SMEs to take full advantage of e-business, Production Planning and Control 12: 548-557. https://doi.org/10.1080/09537280110042891

Chien, K.; Wu, Z.; Haung, S. 2014. Identifying and assessing critical risk factors for BIM projects: Empirical study, Automation in Construction 45: 1-15. https://doi.org/10.1016/j.autcon.2014.04.012

CIOB. 2010. A report exploring procurement in the construction industry. London: The Chartered Institution of Building.

Cox, S.; Clamp, H.; Udom, K.; Lupton, S. 2011. Which contract? Choosing the appropriate building contract. $5^{\text {th }}$ ed. London: RIBA Publishing.

Czaja, R.; Blair, J. 1996. Designing surveys: A guide to decisions and procedures. Thousand Oaks, California, London: Pine Forge Press.

Department for Business Innovation \& Skills. 2014. Statistical release: Business population estimates for the UK and regions 2014 [online], [cited 25 Nov 2015]. Available from Internet: https:/www.gov.uk/government/uploads/system/uploads /attachment_data/file/377934/bpe_2014_statistical_release.pdf

Department for Business Innovation \& Skills. 2013. UK Construction: an economic analysis of the sector. July, 2013.

Eadie, R.; Browne, M.; Odeyinka, H.; McKeown, C.; McNiff, S. 2015. A survey of current status of and perceived changes required for BIM adoption in the UK, Built Environment Project and Asset Management 5(1): 4-21. https://doi.org/10.1108/BEPAM-07-2013-0023

Eastman, C.; Teicholz, P.; Sack, R.; Liston, K. 2011. BIM handbook: a guide to Building Information Modeling for owners, managers, designers, engineers, and contractors. $2^{\text {nd }} \mathrm{ed}$. The United States of America: John Wiley \& Son, Inc.

European Commission. 2015. What is an SME? [online], [cited 18 Nov 2015]. Available from Internet: http://ec.europa. eu/growth/smes/business-friendly-environment/sme-definition/index_en.htm 
Eurostat. 2012. EU SMEs in 2012: at the crossroads [online], [cited 22 Oct 2015]. Available from Internet: http://ec.europa.eu/ enterprise/policies/sme/facts-figures-analysis/performance-review/files/supporting-documents/2012/annual-report_en.pdf

Federation of Master Builders. 2013. Improving public procurement for construction SMEs. UK: Federation of Master Builders.

Ferreira, S.; Collofello, J.; Shunk, D.; Mackulak, G. 2009. Understanding the effects of requirements volatility in software engineering by using analytical modeling and software process simulation, The Journal of Systems \& Software 82(10): 1568-1577. https://doi.org/10.1016/j. jss.2009.03.014

Fewings, P. 2013. Construction project management. An integrated approach. $2^{\text {nd }}$ ed. Abingdon, Oxon: Routledge.

Franks, J. 1998. Building procurement systems - A client's guide. $3^{\text {th }}$ ed. London: Longman.

Furneaux, C.; Kivit, R. 2008. BIM: Implications for government. CRC for Construction Innovation. Brisbane Australia. Net Pty Ltd., 10-31.

Gordon, C. M. 1994. Choosing appropriate construction contracting method, Journal of Construction, Engineering and Management 120(1): 196-210. https://doi.org/10.1061/ (ASCE)0733-9364(1994)120:1(196)

Hadi-Vencheh, A.; Niazi-Motlagh, M. 2011. An improved voting analytic hierarchy process-data envelopment analysis methodology for supplier's selection, International Journal of Computer Integrated Manufacturing 24(3): 189-197. https://doi.org/10.1080/0951192X.2011.552528

Hardin, B. 2009. BIM and construction management: proven tools, methods, and workflows. Indianapolis, Indiana: Wiley Publishing Inc.

Harris, R.; McAdam, R.; McCausland, I.; Reid, R. 2013. Levels of innovation within SMEs in peripheral regions: the role of business improvement initiatives, Journal of Small Business and Enterprise Development 20(1): 102-124. https://doi.org/10.1108/14626001311298439

Hatmoko, J. U. D.; Scott, S. 2010. Simulating the impact of supply chain management practice on the performance of medium-sized building projects, Construction Management and Economics 28(1): 35-49.

https://doi.org/10.1080/01446190903365632

Hogg, K.; Ashworth, A. 2007. Will's practice and procurement for the quantity survey. $12^{\text {th }}$ ed. UK: Blackwell Publishing.

Hsu, J. L.; Cheng, M. C. 2012. What prompts small and medium enterprises to engage in corporate social responsibility? A study from Taiwan, Corporate Social Responsibility and Environmental Management 19: 288-305. https://doi.org/10.1002/csr.276

Hughes, W.; Hillebrandt, P.; Greenwood, D.; Kwawu, W. 2006. Procurement in the construction industry. Abingdon: Taylor and Francis.

Ibrahim, A. B.; Goodwin, J. R. 1986. Perceived causes of success in small business, American Journal of Small Business 11(2): 41-49.

Industry Canada. 2011. Key small business statistics - July 2011 [online], [cited 22 Oct 2014]. Available from Internet:

http://stratgies.ic.gc.ca/epic/site/sbrp-rppe-nsf/en/rd02030e.html

Jaafar, M.; Nuruddin, A. R. 2012. The development of public and private construction procurement systems in the Malaysian construction industry, Journal of Design and Built Environment 11.

Jung, Y.; Joo, M. 2011. Building information modelling (BIM) framework for practical implementation, Automation in Construction 20(2): 126-133.

https://doi.org/10.1016/j.autcon.2010.09.010

Jutla, D.; Bodorik, P.; Dhaliwal, J. 2002. Supporting the e-business readiness of small and medium sized enterprises: approach and metrics, Internet Research 12(2): 139-164.

https://doi.org/10.1108/10662240210422512
Kassem, M.; Kelly, G.; Dawood, N.; Serginson, M.; Lockley, S. 2015. BIM in facilities management applications: a case study of a large university complex, Built Environment Project and Asset Management 5(3): 216-277. http://dx.doi.org/10.1108/BEPAM-02-2014-0011

Kirs, P. J.; Sanders, G. L.; Cerveny, R. P.; Robey, D. 1989. An experimental validation of the Gorry and Scott Morton framework, MIS Quarterly 13(2): 183-197. https://doi.org/10.2307/248926

Kouider, T. 2013. Architectural technology: The defining features, in Conference Proceedings of the $4^{\text {th }}$ International Congress of Architectural Technology, 2013, Sheffield, UK.

Lahdenperä, P. 2012. Making sense of the multi-party contractual arrangements of project partnering, project alliancing and integrated project delivery, Construction Management and Economics 30(1): 57-79. https://doi.org/10.1080/014 46193.2011.648947

Levy, F. 2012. BIM in small-scale sustainable design. Hoboken, New Jersey: Wiley.

Li, B.; Fu, F. F.; Zhong, H.; Luo, H. B. 2012. Research on the computational model for carbon emissions in building construction stage based on BIM, Structural Survey 30(5): 411-425. https://doi.org/10.1108/02630801211288198

Light, D. 2011. BIM implementation - HOK BuildingSMART [online], [cited 23 March 2014]. Available from Internet: http://www.thenbs.com/topics/bim/articles/BIM-Implementation HOKbuildingSMART.asp

Liu, R.; Issa, R.; Olbina, S. 2010. Factors influencing the adoption of building information modelling in the AEC industry, in The International Conference on Computing in Civil and Building Engineering, 2010, Nottingham University, UK.

Liu, Z.; Osniani, M.; Demian, P.; Baldwin, A. 2015. A BIMaided construction waste minimisation framework, Automation in Construction 59: 1-23. https://doi.org/10.1016/j. autcon.2015.07.020

Love, P. E. D.; Irani, Z.; Standing, C.; Lin, C.; Burn, J. M. 2004. The enigma of the evaluation: benefits, costs and risks of IT in Australian small medium sized enterprises, Information and Management 42(3): 947-964.

Luu, D. T.; Nguyen, T.; Chen, S. 2013. Decision criteria and their subjectivity in construction procurement selection, The Australian Journal of Construction Economics and Building 2(1): 70-80.

Luu, D. T.; Ng, S. T.; Chen, S. E. 2005. Formulating procurement selection criteria through case-based reasoning approach, Journal of Computing in Civil Engineering 19(3): 269-276. https://doi.org/10.1061/(ASCE)08873801(2005)19:3(269)

MacLeamy, P. 2004. MacLeamy curve, in Collaboration, Integrated Information, and the Project Lifecycle in Building Design and Construction and Operation (WP-1202). CURT, August, 2004.

Marjanavie, D.; Bojcetie, N.; Osman, K. 2010. Multi criteria decision making in product platform development and evaluation, in International Design Conference - Design 2010, 17-20 May 2010, Dubrovnik, Croatia.

Masterman, J. W. E. 2002. An introduction to building procurement systems. $2^{\text {nd }}$ ed. London: Spon Press.

Migilinskas, D.; Popov, V.; Juocevicius, V.; Ustinovichius, L. 2013. The benefits, obstacles and problems of practical BIM implementation, Procedia Engineering 57: 767-774. https://doi.org/10.1016/j.proeng.2013.04.097

Nahapeit, H.; Nahapeit, J. 1985. The management of construction projects, case studies from UK and USA. UK: Chartered of Institution of Building.

Naoum, S. 2003. An overview into the concept of partnering, International Journal of Project Management 21(1): 71-76. https://doi.org/10.1016/S0263-7863(01)00059-X 
NBS. 2013. NBS National, BIM Report 2013.

NBS. 2015. NBS Nationl BIM Report 2015.

Negendahl, K. 2015. Building performance simulation in the early design stage: An introduction to integrated dynamic models, Automation in Construction 54: 39-53. https://doi.org/10.1016/j.autcon.2015.03.002

Office for National Statistics. 2014. Statistical bulletin: Output in the construction industry, February 2014 [online], [cited 25 Nov 2015]. Available from Internet: http://www. ons.gov.uk/ons/rel/construction/output-in-the-construction-industry/february-2014/stb-construction-feb-2014. html? format=print

Oti, A. H.; Tizani, W. 2015. BIM extension for the sustainability appraisal of conceptual steel design, Advanced Engineering Informatics 29(1): 28-46. https://doi.org/10.1016/j. aei.2014.09.001

Penttilä, H.; Rajala, M.; Freese, S. 2007. Building information modelling of modern historic buildings. Case study of HUT / Architectural Department by Alvar Aalto, in $25^{\text {th }}$ eCAADe Conference Proceedings, 607-613.

Porwal, A.; Hewage, K. 2013. Building information modeling (BIM) partnering framework for public construction projects, Automation in Construction 31: 204-214. https://doi.org/10.1016/j.autcon.2012.12.004

RICS. 2014. International BIM implementation guide. QS \& Construction Professional Group. $1^{\text {st }}$ ed., September 2014.

Robson, A.; Boyd, D.; Thurairajah, N. 2014. UK construction supply chain attitudes to BIM, in $50^{\text {th }}$ ASC Annual International Conference, 2014, Birmingham, UK.

Shepherd, L. M. 2004. Virtual building for construction projects, Virtual Building for Construction Projects 24(1): 6-12.

Singh, V.; Gu, N.; Wang, X. 2011. A theoretical framework of a BIM-based multi-disciplinary collaboration platform, $A u$ tomation in Construction 20(2):134-144. https://doi.org/10.1016/j.autcon.2010.09.011

SmartMarket Report. 2012. The business value of BIM in North America: Multi-year trend analysis and user ratings (2007-2012). Bedford: McGraw- Hill Construction.
SmartMarket Report. 2014. The business value of BIM for construction in major global markets: How contractors around the world are driving innovation with building information modelling. Bedford: McGraw- Hill Construction.

Song, S.; Yang, J.; Kim, N. 2012. Development of a BIM-based structural framework optimization and simulation system for building construction, Computer in Industry 63(9): 895-912. https://doi.org/10.1016/j.compind.2012.08.013

Squires, G.; Greenhagh, B. 2011. Introduction to building procurement. London and New York: Spon press.

Succar, B. 2012. BIM education, BIM in practice. The Australian Institute of Architects and Consult Australia.

Succar, B.; Sher, W.; Williams, A. 2013. An integrated approach to BIM competency assessment, acquisition and application, Automation in Construction 35: 174-89.

https://doi.org/10.1016/j.autcon.2013.05.016

Takim, R.; Akintoye, A.; Kelly, J. 2004. Analysis of performance measurement in the Malaysian construction industry, in Proceeding of Globalization and Construction, 2004, AIT Conference Centre, Bangkok, Thailand.

The Chartered Institution of Building. 2010. A report exploring procurement in the construction industry. London.

Volk, R.; Stengel, J.; Schultmann, F. 2014. Building information modelling (BIM) for existing building - Literature review and future needs, Automation in Construction 38: 109-127. https://doi.org/10.1016/j.autcon.2013.10.023

Won, J.; Lee, G.; Dossick, C.; Messner, J. 2013. Where to focus for successful adoption of Building Information Modeling within organization, Journal of Construction Engineering \& Management 139(11): 1-10. https://doi.org/10.1061/ (ASCE)CO.1943-7862.0000731

Wong, C, H.; Holt G. D.; Cooper, P. A. 2000. Lowest price or value? Investigation of UK construction clients' tender selection process, Construction Management and Economics 18: 67-74. https://doi.org/10.1080/014461900433050

Yang, J.; Peng, C. 2008. Development of a customer satisfaction evaluation model for construction project management, Building and Environment 43(4): 458-468. https://doi.org/10.1016/j.buildenv.2006.07.044

Thep Thanh LAM. He is a PhD research student in the Department of Architecture and the Built Environment, University of the West of England. He is also a Division Head, Information Technology Projects Research and Implementation Department, Ca Mau City, Viet Nam. His research interests include investigating the influences of information technology on innovation and improvement in business, education and the construction industry. He is currently examining the risks and rewards that SMEs may face when they adopt Building Information Modelling (BIM) to deliver construction projects.

Lamine MAHDJOUBI. He is Professor of ICT in Built Environment and Director of the Centre for Architecture and Built Environment Research at the University of the West England, Bristol. He leads the interdisciplinary Building Information Modelling Research Group. One of the key interests is developing the next generation of BIM methods and tools for SMEs. He has extensive experience in developing novel computer-based simulation techniques, and design decision-support tools to examine user-built environment interaction. His research on developing a new generation of BIM methods and tools led to the creation of novel virtual prototyping techniques, the development of an improved methodology for spatial planning, and a series of tools for evaluation, visualisation and optimisation of design solutions.

Jim MASON. Dr, Programme Director of the Masters in International Construction Law in the Department of Architecture and Built Environment at the University of the West of England. Jim joined the University in 2002 after ten years spent in private practice as a construction law specialist. The subject of Jim's DPhil in 2012 investigated the socio-legal impact on different forms of legal initiatives on the construction industry. The culmination of the teaching and research in construction law can be accessed via the textbook to be published in 2016 entitled "Construction Law and Process: From Beginner to Practitioner". 